\title{
Structure and fragmentation of growling grass frog metapopulations
}

5

6 Joshua M. Hale ${ }^{1,2,3}$ * Geoffrey W. Heard ${ }^{3,4}$, Katie L. Smith ${ }^{1,2,3}$, Kirsten M. Parris ${ }^{3}$, Jeremy J.

$7 \quad$ Austin $^{1,5}$, Michael Kearney ${ }^{2}$ and Jane Melville ${ }^{1}$

$8 \quad{ }^{1}$ Sciences Department, Museum Victoria, Melbourne 3053, Australia

$9 \quad{ }^{2}$ Department of Zoology, University of Melbourne, Melbourne 3010, Australia

$10 \quad{ }^{3}$ School of Botany, University of Melbourne, Melbourne 3010, Australia

$11{ }^{4}$ Department of Zoology, La Trobe University, Bundoora, 3086, Australia

$12{ }^{5}$ Australian Centre for Ancient DNA, University of Adelaide, Adelaide 5005, Australia

14 Corresponding author: Joshua Hale

15 Sciences Department, Museum Victoria, Melbourne, VIC 3053, Australia

16 Phone: 613 83417487; Fax: 613 83417442; Email: jhale@ museum.vic.gov.au

18 Running title: Structure and fragmentation of frog metapopulations

20 Keywords: endangered, growling grass frog, metapopulation, habitat fragmentation,

21 microsatellites, urbanization. 


\section{Abstract}

23 Metapopulations occur in fragmented landscapes, and consist of demographically-

24 independent populations connected by dispersal. Nevertheless, anthropogenic habitat

25 fragmentation may be fatal to metapopulations, as it disrupts dispersal and gene flow, and

26 undermines the balance between population extinction and colonization. Understanding the

27 extent to which particular land-use practices disrupt dispersal and gene flow is therefore

28 crucial for conserving metapopulations. We examined the structure and fragmentation of

29 metapopulations of the endangered growling grass frog (Litoria raniformis) in an urbanizing

30 landscape in southern Australia. Population clustering analyses revealed three distinct genetic

31 units, corresponding to the three wetland clusters sampled. Isolation-by-distance was

32 apparent between populations, and genetic distance was significantly correlated with the

33 presence of urban barriers between populations. Our study provides evidence that

34 urbanization fragments metapopulations of $L$. raniformis. Managers of L. raniformis in

35 urbanizing landscapes should seek to mitigate effects of urbanization on dispersal and gene

36 flow. 
Many species are organised as metapopulations. Examples range from herbs and forbs

(Menges 1990; Ouborg 1993; Harrison and Ray 2002), through invertebrates and small vertebrates (Verboom et al. 1991; Hanski et al. 1994; Kindvall 1996; Sjögren-Gulve 1994; Moilanen et al. 1998), to larger vertebrates in both terrestrial and marine systems (Possingham et al. 1994; Lahaye et al. 1994; Harveson et al. 2006; Kritzer and Sale 2006). While the structure and dynamics of metapopulations varies considerably across these diverse guilds, a feature common to all is habitat patchiness arising from either natural or anthropogenic fragmentation. Metapopulations are defined as networks of spatially discrete populations connected by dispersal (Hanski and Simberloff 1997). Habitat fragmentation is becomes non-random (Hanski 1998, 1999).

Despite this, metapopulations are sensitive to the level of habitat fragmentation they experience, particularly that arising from human land-use practices (Lindenmayer and Fischer 2006). While constraints on dispersal are required for metapopulations to form, sufficient dispersal between populations is also necessary to ensure that the rate of population extinction does not exceed the rate of patch colonization (Hanski 1998, 1999). Dispersal rate is clearly central to the rate of patch colonization; the more immigrants that a patch receives, the more likely establishment is (Ebenhard 1991). However, dispersal rate may also influence the rate of population extinction (Gaggiotti and Hanski 2004). From a demographic perspective, immigration from neighboring populations bolsters population size. Larger populations are less sensitive to demographic and environmental perturbations, and are therefore less prone to extinction (Brown and Kodric-Brown 1977; Hanski 1998, 1999). From 
a genetic perspective, immigration allows outcrossing, leading to the avoidance or alleviation

64

65

66

67

68

69

70

71

72

of inbreeding depression in many species (Frankham et al. 2009). Immigration may also alleviate the deleterious effects of reduced genetic diversity in small, isolated populations (Reed and Frankham 2003).

There are two primary means by which anthropogenic habitat fragmentation can produce unsustainable reductions in the rate of dispersal within metapopulations. The first, and most intuitive, is its effect on the physical ability of migrants to move between patches. Increased inter-patch distances, the removal of dispersal corridors and the construction of particular types of human infrastructure may all reduce the physical capability of migrants to move across landscapes (Hanski 1999; Suter et al. 2007). The second is its effect on the size of the constituent populations. When habitat fragmentation reduces patch size or enhances edge effects, there will be, in most cases, a concomitant reduction in population size (Hanski 1998, 1999; Gaggiotti and Hanski 2004). Larger populations produce the most migrants, so changes in the size or quality of particular patches can lead to significant reductions in the overall rate of dispersal (Hanski 1999).

Of the various human land-use practices that fragment the habitat of plants and animals, urbanization is a key concern. Some 3.3 billion people currently inhabit urban centers worldwide, and this figure is expected to rise to 5 billion by 2030 (UNFPA 2007). The construction of housing and transport infrastructure to support these human population trends typically requires the destruction of habitat remnants, or parts thereof (McKinney 2002). Moreover, urban infrastructure represents a significant barrier to dispersal for many taxa, leading to considerable reductions in landscape permeability (Trombulak and Frissell 2000). 
Urbanization-driven habitat fragmentation is of considerable concern for the conservation of amphibians (Cushman 2006; Hamer and McDonnell 2008). Amphibians are now one of the most threatened components of many ecosystems worldwide, with one third of all species currently at risk of extinction (Stuart et al. 2004; Beebee and Griffiths 2005). The effects of urbanization on amphibians can be multifarious; however, habitat fragmentation is a prominent risk, because many are reliant on metapopulation dynamics for persistence (Cushman 2006; Hamer and McDonnell 2008). However, habitat fragmentation is also problematic for the many amphibians that display patchy-population dynamics (sensu Harrison and Taylor 1997), in which individuals regularly migrate between wetlands in response to changing conditions, or between wetlands and surrounding terrestrial zones as part of seasonal changes in activity patterns (Marsh and Trenham 2001; Smith and Green 2005). Dispersal is obviously central to these dynamics, so processes that impede dispersal can also have significant detrimental outcomes for amphibians that display them (Semlitsch 2002, 2003; Cushman 2006; Baldwin et al. 2006).

This study extends recent ecological research on the metapopulation dynamics of the endangered growling grass frog (Litoria raniformis) in the urbanizing landscapes of Melbourne, Victoria, Australia (Heard et al. 2012). Litoria raniformis is a large, highly aquatic frog that was once widespread across south-eastern Australia (Pyke 2002), yet has suffered substantial population declines (Mahony 1999; Wassens 2008; Hamer et al. 2010). There is concern that urbanization fragments remnant populations of L. raniformis in the vicinity of Melbourne, and undermines their viability (Hamer and Organ 2008; Heard et al. 2010). However, empirical evidence of the effect of urban development on dispersal and gene flow has been lacking. We used microsatellite markers to investigate the pattern of population subdivision for L. raniformis across an urban gradient on the northern outskirts of Melbourne. 
We predicted strong clustering of genetic similarity, consistent with the view that clusters of wetlands support discrete metapopulations of the frog (Heard et al. 2012). Between populations, we predicted isolation-by-distance effects consistent with a sharp decline in the rate of dispersal with distance, and resulting low rate of migration (Heard et al. 2012). Overlain on this pattern we predicted a signal of urbanization-driven habitat fragmentation, in the form of increased genetic distance between populations separated by major urban infrastructure.

\section{Materials and Methods}

\section{Study area}

123

This study was conducted in the Merri Creek catchment (MCC) on the northern fringe of Melbourne (Figure 1). The Merri Creek originates in the Great Dividing Range approximately $50 \mathrm{~km}$ north-east of Melbourne, and flows south to its confluence with the Yarra River approximately $5 \mathrm{~km}$ north-east of the central business district. The topography is undulating, with a largely volcanic geology. Land-use within the catchment displays a clear gradient from predominantly livestock-based agriculture in the north to urban development in the south (Figure 1). Current plans for Melbourne's urban growth propose development of much of the MCC over the next 20 years (DPCD 2009).

\section{Tissue sampling}

Litoria raniformis were sampled at 12 sites across the middle reaches of the MCC during the 2004/2005 and 2005/2006 breeding seasons (Figure 1). These sites were distributed in three distinct clusters (northern, central and southern), each separated by approximately $6 \mathrm{~km}$. Site 
selection proceeded with dual aims of enabling detection of dispersal during a concomitant mark-recapture study (Heard et al. 2012), and to sample sites that varied in their distance to others in the network and in their degree of isolation by urban barriers. Sites included chains of pools along the Merri Creek and two of its ephemeral tributaries, and lentic wetlands including farm dams, natural and artificial ponds, swamps and quarries. Major barriers included housing and industrial estates, and two dual-carriage roads (Cooper Street and the Hume Freeway; Figure 1b). In the northern cluster, a single major barrier (the Hume Freeway) separated site N1 from all others (Figure 1c). Sites S1 and S2 in the southern cluster were separated by industrial estates (Figure 1e).

Each site was surveyed repeatedly between October and March, and capture by hand or net was attempted for all L. raniformis located. Tissue samples were obtained from all captured frogs by clipping the toe-pad on the left middle digit of the front left limb, following standard sterile techniques (Ferner 2007). Clipped toes were stored in 90\% ethanol. To avoid double sampling (and for the purposes of the mark-recapture study) all frogs were marked by subcutaneous injection of either a Passive Integrated Transponder (PIT) tag (Trovan Ltd, East Yorkshire, UK), or a Visible Implant Alphanumeric (VIA) tag (Northwest Marine Technology, Shaw Island, WA, USA). Genetic contamination and disease transmission was locations and sampling intensities are summarized in Table 1.

Microsatellite analysis

159 Genomic DNA was extracted using a standard Proteinase K digestion and chloroform: 160 isoamyl alcohol extraction protocol (Gemmell and Akiyama 1996 ). Eleven polymorphic 
microsatellite markers were used. Nine were developed specifically for this study system (Hale et al. 2011) and a further two taken from previous research on the closely-related species, Litoria aurea (Laurea2A, Laurea5M; Burns and Ferrari 2004). See Hale et al. (2011) for PCR information and conditions for the nine novel loci, as well as methods for fluorescently labelling fragments for all loci. PCR conditions for the two previously published loci were different than for the other loci: $95^{\circ} \mathrm{C} 5 \mathrm{~min}, 2$ cycles of $95^{\circ} \mathrm{C} 30 \mathrm{~s}, 66^{\circ} \mathrm{C}$ $30 \mathrm{~s}, 72^{\circ} \mathrm{C} 60 \mathrm{~s} ; 2$ cycles of $95^{\circ} \mathrm{C} 30 \mathrm{~s}, 64^{\circ} \mathrm{C} 30 \mathrm{~s}, 72^{\circ} \mathrm{C} 60 \mathrm{~s} ; 42$ cycles of $95^{\circ} \mathrm{C} 30 \mathrm{~s}, 62^{\circ} \mathrm{C} 30$ s, $72^{\circ} \mathrm{C} 60 \mathrm{~s}$, followed by $72^{\circ} \mathrm{C} 5$ min (adapted from Burns and Ferrari 2004). PCR products were diluted for fragment analysis which was carried out by the Australian Genome Research Facility (AGRF) on an Applied Biosystems ABI3730 DNA analyser using a LIZ-500 size standard. Scoring was completed using Genemapper version 3.1.2 and Peak Scanner version 1.0 (Applied Biosystems). All samples were manually screened for accuracy.

\section{Statistical analyses}

The frequency of null alleles was calculated using the program FreeNA (Chapuis and Estoup 2007). We tested for gametic disequilibrium between loci using Fisher's exact test, and deviations from Hardy-Weinberg Equilibrium (HWE) were tested using a U test. Both were implemented in Genepop version 4.0 (Rousset 2008). Parameters used for these analyses were a burn-in period (dememorisation) of 10,000, 100 batches and 1000 iterations. Two sites (C4 and C5) were excluded from these analyses due to low sample sizes. Observed and expected heterozygosity $\left(H_{\mathrm{O}}\right.$ and $H_{\mathrm{E}}$, respectively) were estimated in GenAlex version 6.3 (Smouse and Peakall 2006). Sequential Bonferroni adjustments for multiple comparisons were made when required. 
We estimated the number of genetic units in the full data set, as well as within each site cluster (northern, central and southern) using the Bayesian population clustering program Structure version 2.3.2 (Pritchard et al. 2000; Pritchard et al. 2010). We used a model that assumed uncorrelated allele frequencies (to reduce the likelihood of overestimating $K$ ) and admixture (the recommended starting point for the model). The LOCPRIOR model was used, which implicitly incorporates putative population information (in this case, geographic location). This model can help to detect genetic structure in the data, especially when the signal is relatively weak (Pritchard et al. 2010). We repeated each analysis with varying admixture states and excluding locational information. The results were concordant with the admixture/LOCPRIOR model. For all analyses, inferences were derived from 500,000 MCMC samples, after discarding the first 100,000 samples as a 'burn-in'. The number of genetic units $(K)$ was set a priori to range from 1-13 (to encompass 12 , the number of sampling sites). Simulations were run 10 times for each proposed $K$ between 1 and 13. To the three site clusters followed the same procedure, varying $K$ from 1 to 8 . 10 runs to determine which value of $K$ had the highest posterior probability or the smallest value of $K$ among estimates at a plateau of highest values (Pritchard et al. 2010). Analysis of

Pairwise $F_{\text {ST }}$ between sites was estimated using Arlequin version 3.1 (Excoffier et al. 2005). As above, sites $\mathrm{C} 4$ and $\mathrm{C} 5$ were excluded from this analysis given sample size constraints. We used partial Mantel tests to assess the relationship between pairwise $F_{\mathrm{ST}}$ and both geographic distance and the presence of major urban barriers between sites. Partial Mantel tests allow the correlation between two distance matrices to be quantified whilst controlling for correlations with additional matrices (Smouse et al. 1986). Straight-line distances between wetland centres were used (see Tables 1 and 2) as L. raniformis is known to migrate overland 
through pasture, grassland and shrubland (see Heard et al. 2012), and was therefore capable of selecting the shortest route between any two of our sampling locations. Pairs of sites were defined as being separated by major urban barriers if the straight-line distance between them crossed housing or industrial estates, or dual-carriage roads. After Cushman et al. (2006), we ran two partial Mantel tests; one in which the correlation between pairwise $F_{\mathrm{ST}}$ and the presence of barriers was tested while partialling out distance, and the other in which the correlation between pairwise $F_{\mathrm{ST}}$ and distance was tested while partialling out the barrier effect. If distance and barriers both influence pairwise $F_{\mathrm{ST}}$ (as we anticipated), the correlation coefficients for both relationships should be independently significant. Partial Mantel tests were performed in $R$ version 2.13.0 (R Development Core Team 2012) using the add-in package ecodist version 1.2.7 (Goslee and Urban 2012). Significance of the correlation coefficients was assessed using 10,000 random permutations of the first matrix, as described by Goslee and Urban (2007).

\section{Results}

A high frequency of null alleles (greater than 10\%) was observed for four loci at three sampling sites. Locus Laurea5M showed a high frequency of null alleles at sampling site S1, Laurea2A and Lr8 at C1 and Lr3 at sampling site N3. Given the inconsistent pattern of null allele detection, all loci were retained for subsequent analyses. No significant gametic disequilibrium was observed for any locus pair across each population. Heterozygosity levels are presented in Table 1.

Bayesian population clustering tests including all samples (Figure 2a) revealed three distinct genetic units $(K=3)$ (average $\operatorname{Ln} \operatorname{Pr}(X \mid K)=-6787.9)$. These units correspond with the three major geographic site clusters (northern, central and southern). Analysis of samples from 
within the northern cluster revealed two distinct genetic units (average $\operatorname{Ln} \operatorname{Pr}(X \mid K)=-$ 3140.2), separating samples from site N1 from all others in that cluster (Figure $2 \mathrm{~b}$ ). The analysis therefore suggests a genetic division between sites east of the freeway in this cluster from the remainder west of the freeway. However, the analysis suggests some gene flow between $\mathrm{N} 1$ and the other four sampling sites in the northern cluster, with admixture being particularly apparent in sites N2, N3 and N4 (Figure 2b). For the central cluster, in which no major urban barriers occurred between sites, $K=1$ had the highest posterior probability (average $\operatorname{Ln} \operatorname{Pr}(X \mid K)=-2236.5)$. There were clear genetic differences between the two sites in the southern cluster; $K=2$ had the highest posterior probability (average $\operatorname{Ln} \operatorname{Pr}(X \mid K)=$ 1232.44), and there was little admixture between the two sites (Figure 2c).

Pairwise $F_{\mathrm{ST}}$ values were always significant following sequential Bonferroni correction when sites were located in different clusters (Table 2). Within clusters, all pairwise $F_{\mathrm{ST}}$ values between sites separated by major urban development were significant. Of the eight withincluster site pairings for which there was no major urban development between them, two displayed significant pairwise $F_{\mathrm{ST}}$ values. Partial Mantel tests revealed significant correlations between pairwise $F_{\mathrm{ST}}$ and both the presence of urban barriers ( $r=0.379$, twosided $p=0.019)$ and geographic distance $(r=0.569$, two-sided $p=0.0003)$. Figure 3 compares the relationship between pairwise $F_{\mathrm{ST}}$ and geographic distance for sites within the same cluster, with and without major urban barriers between them.

\section{Discussion}

Our study supports earlier ecological research on the spatial dynamics of $L$. raniformis in this region. On the basis of wetland occupancy and mark-recapture data, Heard et al. (2012) concluded that the dynamics of $L$. raniformis across northern Melbourne resemble classical 
metapopulation dynamics (sensu Hanski 1999), with clusters of wetlands spread over distances of 1-2 km supporting discrete metapopulations of the frog, and wetlands within clusters supporting demographically-independent populations connected by infrequent, distance-limited dispersal. Our Bayesian population clustering analyses revealed three distinct genetic units, corresponding with the three wetland clusters sampled (Figure 2a). They also suggested minimal admixture between the three clusters. These results clearly support the notion that clusters of wetlands support discrete metapopulations of L. raniformis across northern Melbourne. Bayesian population clustering analyses also revealed genetic sub-divisions within two of the three wetland clusters. These sub-divisions correlated with the occurrence of major barriers to dispersal in both cases (see further below); however, significant pairwise $F_{\mathrm{ST}}$ values between site $\mathrm{N} 2$ and both $\mathrm{N} 3$ and $\mathrm{N} 5$ in the northern cluster, which were not separated by urban barriers, are suggestive of additional population subdivision in this area. Given that sites N3 and N5 were the furthest from N2 (excluding N4, for which relatively few samples were obtained), this result is consistent with the strong isolation-by-distance effect suggested by the previous ecological study (Heard et al. 2012) and by our broader genetic data.

Nevertheless, the lack of genetic sub-divisions within the central cluster may be evidence of higher rates of dispersal by L. raniformis in some situations than those suggested by the previous demographic study (Heard et al. 2012). In this area, two of three sites for which adequate samples were obtained (C1 and $\mathrm{C} 2)$ occurred along Merri Creek, and may have displayed relatively high rates of migration and genetic exchange for this reason. Higher rates of dispersal between adjacent sites, or between those connected by streams, could undermine their treatment as demographically-independent populations connected by infrequent dispersal, and instead point to a mixture of metapopulation and patchy-population processes 
within clusters (Harrison and Taylor 1997; Marsh and Trenham 2001; Smith and Green 2005; see also Hamer et al. 2008; Wassens et al. 2008). We acknowledge that treating some populations as being discrete from their neighbours may be problematic. However, it is also important to note that genetic panmixia does not necessarily imply demographic panmixia, because the rate of migration needed to maintain genetic cohesion may be far less than that required for demographic cohesion (Lowe and Allendorf 2010). Moreover, in our study area, the very sharp decay in the probability of dispersal with distance suggested by the previous mark-recapture study is an important determinant of wetland occupancy and colonisation by L. raniformis, including occupancy and colonisation of pools along streams (Heard et al. 2012). Given this, and the strong correlation between genetic distance and geographic distance detected in our study, we conclude that dispersal by L. raniformis is strongly distance-limited, and that metapopulation theory provides a useful overall model of the dynamics of the species in this region.

As well as inter-patch distance, this study provides evidence that major urban infrastructure affects the rate of dispersal and gene flow for L. raniformis in urbanizing landscapes. Bayesian population clustering tests identified genetic sub-division between all populations separated by major urban infrastructure (housing and industrial estates, and dual carriage roads), and pairwise $F_{\mathrm{ST}}$ values were correlated with the presence of urban barriers between early genetic study, Hitchings and Beebee (1997) found substantially increased genetic differentiation between populations of the Common Frog (Rana temporaria) in an urban setting relative to those within a rural landscape. The same result was observed for the 
and Sietz (1990), Vos et al. (2001) and Arens et al. (2006) explicitly tested the relationship between genetic distance and the extent of urbanization between populations of the Moor Frog (Rana arvalis) and Common Frog (R. temporaria) in Europe. Each of these studies indentified important correlations between genetic distance and urbanization.

These studies, and ours, provide evidence that urban infrastructure impedes dispersal and gene flow for amphibians. However, each has relied on correlative analyses to assess relationships between genetic distance and the extent of urbanization. Correlative analyses represent a relatively weak basis to infer cause and effect, because spurious relationships between the independent and supposed dependent variable may arise (Burnham and Anderson 2002; Williams et al. 2002; Cushman et al. 2006). Nevertheless, there are two reasons to believe that urbanization does indeed fragment populations of amphibians, including L. raniformis. Firstly, relationships between urbanization and both genetic and ecological measures of dispersal rate are consistently identified for amphibians (above), in which case the supposed cause and effect relationships between these variables becomes increasingly plausible (Burnham and Anderson 2002; Williams et al. 2002). Secondly, there are clear mechanisms underlying the supposed effects of urbanization on amphibian dispersal. Amphibians may actively avoid urban areas during dispersal, due to the physical barriers to movement these areas present, the lack of free-standing water or moist microhabitats, and the extensive light and noise pollution therein (see Eigenbrod et al. 2009). High mortality rates during attempts to cross urban infrastructure have also been documented for amphibians. For example, Hels and Buchwald (2001) studied the migration behaviour of six species of amphibian in Denmark, and calculated rates of mortality during road crossings. They estimated that the probability of surviving an attempt to cross a motorway could be as low as 0.02 for their study species. 
336 In the preceding sections, we focused on the effect of urban barriers on the internal dynamics

337 of metapopulations; however, urban barriers may also influence extinction and colonization

338 dynamics of entire metapopulations. The dispersal kernels of amphibians often have long

339 tails, resulting from occasional long-distance dispersal events (Smith and Green 2005). Such

340 events may allow important genetic interactions, limiting metapopulation-wide reductions in

341 genetic diversity through inbreeding and drift (Frankham et al. 2009). As such, the placement

342 of urban infrastructure between metapopulations of $L$. raniformis may also threaten their

343 persistence. Our study provides some evidence of this additive form of fragmentation for

344 L. raniformis. Populations sampled in the southern wetland cluster appeared not only to be

345 largely separated from each other, but also from the clusters further north (Figure 2a, c).

346 Resulting reductions in genetic diversity are apparent for the populations in the southern

347 cluster, with both observed heterozygosity and allelic richness being slightly lower for these

348 populations than those in the central and northern clusters (Table 1; Hale 2010).

There are several ways to manage the effects of urbanization on dispersal and gene flow for

L. raniformis. In the first instance, priority should be placed on preserving metapopulations

that are, or will be, less susceptible to internal fragmentation. Metapopulations centered on

in-stream habitat and adjacent off-stream wetlands are the obvious choice in this regard,

because riparian corridors are usually reserved as open space in Melbourne's urbanizing landscapes (DPCD 2009), and because these flood prone areas have limited developable land.

Within metapopulations, placement of major roads and other infrastructure may be manipulated to conserve dispersal pathways (Forman and Alexander 1998). Underpasses are known to facilitate dispersal for various animals, including amphibians (Ng et al. 2004; Mata et al. 2008; Glista et al. 2009), and may represent a means of mitigating barrier effects for 

in recent years, their effectiveness remains unknown (Heard et al. 2010). Research on the efficacy and optimal design of these structures for L. raniformis would be of considerable value.

Maintaining dispersal and gene flow between metapopulations of L. raniformis may be achieved through sympathetic management of the stream network (where metapopulations are connected by streams) and/or the construction of dedicated connecting wetlands. Instream habitat of L. raniformis is characterised by large, slow-flowing pools with dense aquatic vegetation (Heard et al. 2010). It is feasible to create or enhance these features through the installation of weirs or riffle beds, through physical deepening of pools, and through aquatic re-vegetation (Heard et al. 2010). Doing so strategically could establish new populations that connect otherwise disjunct metapopulations. Likewise, constructing or rejuvenating off-stream wetlands may represent a means of establishing new populations, and facilitating gene flow between wetland clusters. Such initiatives have proven successful for other frog species (Petranka et al. 2007; Brand and Snodgrass 2010).

Finally, genetic restoration through the translocation of individuals could be employed to offset the deleterious effects of inbreeding and drift for populations L. raniformis in urban landscapes (Tallmon et al. 2004; Hedrick 2005; Bouzat et al. 2009). However, translocation may also have detrimental effects. Outbreeding depression has been documented for amphibians (Sagvik et al. 2005; Sherman et al. 2008), and represents a legitimate concern. The spread of pathogens between populations is also a major risk, as highlighted by the extinction of numerous amphibian populations following exposure to the chytrid fungus, 
restoration could be employed to maintain or restore genetic diversity of L. raniformis in urbanizing landscapes, the potential demographic and genetic pitfalls associated with this technique require further study.

\section{Acknowledgements}

Funding for this project was provided by an Australian Research Council Linkage Grant (LP0667815). Additional funding was provided to JH from the Holsworth Wildlife Endowment, Museum Victoria and the Loftus-Hills Memorial Grant (University of Melbourne). Tissue collection was conducted by GH with support from a David Myers Postgraduate Scholarship (La Trobe University), and grants from the Growling Grass Frog Trust Fund and Victorian Department of Sustainability and Environment. Manuscript preparation was supported by Australian Research Council Linkage Grant (LP0990161). We thank M. Kearney, M. Littlejohn, B. Malone, M. Scroggie and P. Robertson for expert advice. Technical support was provided by staff of the Sciences Department, Museum Victoria, and the Department of Zoology, La Trobe University. Private landholders in the Merri Creek catchment kindly allowed us access to their properties for sampling purposes.

\section{References}

Arens P, Bugter R, Westende W, Zollinger R, Stronks J, Vos C, Smulders M (2006) Microsatellite variation and population structure of a recovering Tree frog ( Hyla arborea; L.) metapopulation. Conservation Genetics 7:825-835.

Baldwin RF, Calhoun AJK, DeMaynadier PG (2006) Conservation planning for amphibian species with complex habitat requirements: a case study using movements and habitat selection of the Wood Frog Rana sylvatica. Journal of Herpetology 40:442-453 
Beebee TJC, Griffiths RA (2005) The amphibian decline crisis: a watershed for conservation biology? Biological Conservation 125:271-285

Bouzat J, Johnson J, Toepfer J, Simpson S, Esker T, Westemeier R (2009) Beyond the beneficial effects of translocations as an effective tool for the genetic restoration of isolated populations. Conservation Genetics 10:191-201.

Brand AB, Snodgrass JW (2010) Value of artificial habitats for amphibian reproduction in altered landscapes. Conservation Biology 24:295-301

Brown JH, Kodric-Brown A (1977) Turnover rates in insular biogeography: effect of immigration on extinction. Ecology 58:445-449

Burnham KP, Anderson DR (2002) Model Selection and Multi-model Inference: A Practical Information-theoretic Approach. 2nd edn. Springer, New York

Burns EL, Ferrari G (2004) Microsatellite loci for the Green and Golden Bell Frog (Litoria aurea). Conservation Genetics 5:421-423

Chapuis M-P, Estoup A (2007) Microsatellite null alleles and estimation of population differentiation. Molecular Biology and Evolution 24:621-631

Cushman SA (2006) Effects of habitat loss and fragmentation on amphibians: a review and prospectus. Biological Conservation 128:231-240

Cushman SA, McKelvey KS, Hayden J, Schwartz MK (2006) Gene flow in complex landscapes: testing multiple hypotheses with causal modeling. The American Naturalist $168: 486-499$

DPCD (2009) Delivering Melbourne's Newest Sustainable Communities. Victorian Department of Planning and Community Development, Melbourne

Ebenhard T (1991) Colonization in metapopulations: a review of theory and observations. Biological Journal of the Linnean Society 42:105-121 
Eigenbrod F, Hecnar SJ, Fahrig L (2009) Quantifying the road-effect zone: threshold effects of a motorway on anuran populations in Ontario, Canada. Ecology and Society 14:24

Excoffier L, Laval G, Schneider S (2005) Arlequin ver 3.0: an integrated software package for population genetic analysis. Evolutionary Bioinformatics Online 1:47-50

Ferner JW (2007) A review of marking and individual recognition techniques for amphibians and reptiles. Society for the Study of Amphibians and Reptiles, Salt Lake City

Forman RTT, Alexander LE (1998) Roads and their major ecolgical effects. Annual Review Ecology and Systematics 29:207-231

Frankham R, Ballou JD, Briscoe D (2009) Introduction to Conservation Genetics. 2nd edn. Cambridge University Press, New York

Gaggiotti OE, Hanski I (2004) Mechanisms of population extinction. In: Hanski I, Gaggiotti OE (eds) Ecology, Genetics and Evolution of Metapopulations Academic Press, San Diego, pp 337-366

Gemmell NJ, Akiyama S (1996) A simple and efficient method for the extraction of DNA. Trends in Genetics 12:338-339

Glista DJ, DeVault TL, DeWoody JA (2009) A review of mitigation measures for reducing wildlife mortality on roadways. Landscape and Urban Planning 91:1-7.

Goslee SC, Urban DL (2007) The ecodist package for dissimilarity-based analysis of ecological data. Journal of Statistical Software 22:1-19

Goslee SC, Urban DL (2012) ecodist: dissimilarity-based functions for ecological analysis. http://cran.r-project.org/web/packages/ecodist/index.html

Haddad NM (1999) Corridor and distance effects on interpatch movements: a landscape experiment with butterflies. Ecological Applications 9:612-622

Hale JM (2010) Human-induced changes in the population genetic structure of frogs in southeastern Australia. PhD. University of Melbourne, Melbourne 
Hale JM, Heard G, Smith K, Blacket M, Austin J, Melville J (2011) Microsatellite loci for the endangered growling grass frog (Litoria raniformis), with cross amplification in other Australian frog species. Conservation Genetics Resources 3:593-595

Hamer AJ, Lane SJ, Mahony MJ (2008) Movement patterns of adult Green and Golden Bell Frog Litoria aurea and the implications for conservation management. Journal of Herpetology 42:397-407

Hamer AJ, Lane SJ, Mahony MJ (2010) Using probabilistic models to investigate the disappearance of a widespread frog-species complex in high-altitude regions of southeastern Australia. Animal Conservation 13:275-285

Hamer AJ, McDonnell MJ (2008) Amphibian ecology and conservation in the urbanizing world: a review. Biological Conservation 141:2432-2449

Hanski I (1998) Metapopulation dynamics. Nature 396:41-49

Hanski I (1999) Metapopulation Ecology. Oxford University Press, Oxford

Hanski I, Kuussaari M, Neimeinen M (1994) Metapopulation structure and migration in the butterfly Melitaea cinxia. Ecology 75:747-762

Hanski I, Simberloff D (1997) The metapopulation approach: its history, conceptual domain and application to conservation. In: Hanski I, Gilpin ME (eds) Metapopulation Biology: Ecology, Genetics and Evolution. Academic Press, Inc., San Diego, pp 5-26

Harrison S, Ray C (2002) Plant population viability and metapopulation-level processes. In: Beissinger SR, McCullough DR (eds) Population Viability Analysis. University of Chigaco Press, Chicago, pp 109-122

Harrison S, Taylor AD (1997) Empirical evidence for metapopulation dynamics. In: Hanski I, Gilpin ME (eds) Metapopulation Biology. Ecology, Genetics, and Evolution. Academic Press Inc., San Diego, pp 27-42 
Harveson PM, Grant WE, Lopez RR, Silvy NJ, Frank PA (2006) The role of dispersal in Florida Key deer metapopulation dynamics. Ecological Modelling 195:393-401

Heard GW, Scroggie MP, Clemann N (2010) Guidelines for managing the endangered Growling Grass Frog in urbanizing landscapes. Arthur Rylah Insitute for Environmental Research Technical Report Series No. 208. Victorian Department of Sustainbility and Environment, Heidelberg. .

Heard GW, Scroggie MP, Malone BS (2012) Classical metapopulation theory as a useful paradigm for the conservation of an endangered amphibian. Biological Conservation 148:156-166

Hedrick PW (2005) 'Genetic restoration:' a more comprehensive perspective than 'genetic rescue'. Trends in Ecology and Evolution 20:109

Hedrick PW, Kalinowski S (2000) Inbreeding depression in conservation biology. Annual Review Ecology and Systematics 31:139-162

Hels T, Buchwald E (2001) The effects of road kills on amphibian populations. Biological Conservation 99:331-340.

Hitchings SP, Beebee TJC (1997) Genetic substructuring as a result of barriers to gene flow in urban Rana temporaria (common frog) populations: implications for biodiversity conservation. Heredity 79:117-127

Hubisz MJ, Falush D, Stephens M, Pritchard JK (2009) Inferring weak population structure with the assistance of sample group information. Molecular Ecology Resources 9:1322-1332.

Kindvall O (1996) Habitat heterogeneity and survival in a bush cricket metapopulation. Ecology 77:207-214

Kritzer JP, Sale PF (eds) (2006) Marine Metapopulations. Elsevier Academic Press, San Diego 
Lahaye WS, Gutiérrez RJ, Akcakaya HR (1994) Spotted Owl metapopulation dynamics in southern California. Journal of Animal Ecology 63:775-785

Laurance WF, Camargo JLC, Luizão RCC, Laurance SG, Pimm SL, Bruna EM, Stouffer PC, Bruce Williamson G, Benítez-Malvido J, Vasconcelos HL, Van Houtan KS, Zartman CE, Boyle SA, Didham RK, Andrade A, Lovejoy TE (2011) The fate of Amazonian forest fragments: a 32-year investigation. Biological Conservation 144:56-67.

Lindenmayer DB, Fischer J (2006) Habitat Fragmentation and Landscape Change: An Ecological and Conservation Synthesis. Island Press, Washington

Lowe WH, Allendorf FW (2010) What can genetics tell us about population connectivity? Molecular Ecology 19:3038-3051.

Magrach A, Larrinaga AR, SantamarÍA L (2012) Effects of matrix characteristics and interpatch distance on functional connectivity in fragmented temperate rainforests. Conservation Biology 26:238-247.

Mahony M (1999) Review of the declines and disappearances within the bell frog species group (Litoria aurea species group) in Australia. In: Campbell A (ed) Declines and Disappearances of Australian Frogs. Environment Australia, Canberra, pp 81-93

Marsh DM, Trenham PC (2001) Metapopulation dynamics and amphibian conservation. Conservation Biology 15:40-49

Mata C, Hervás I, Herranz J, Suárez F, Malo JE (2008) Are motorway wildlife passages worth building? Vertebrate use of road-crossing structures on a Spanish motorway. Journal of Environmental Management 88:407-415

McKinney ML (2002) Urbanization, biodiversity, and conservation. BioScience 52:883-890.

Menges ES (1990) Population viability analysis for an endangered plant. Conservation Biology 4:52-62 
Moilanen A, Smith AT, Hanski I (1998) Long-term dynamics in a metapopulation of the American Pika. The American Naturalist 152:530-542

Ng SJ, Dole JW, Sauvajot RM, Riley SPD, Valone TJ (2004) Use of highway undercrossings by wildlife in southern California. Biological Conservation 115:499-507

Noël S, Ouellet M, Galois P, Lapointe F-J (2007) Impact of urban fragmentation on the genetic structure of the eastern red-backed salamander. Conservation Genetics 8:599606

Ouborg NJ (1993) Isolation, population size and extinction: the classical and metapopulation approaches applied to vascular plants along the Dutch Rhine-system. Oikos 66:298-308

Petranka JW, Harp EM, Holbrook CT, Hamel JA (2007) Long-term persistence of amphibian populations in a restored wetland complex. Biological Conservation 138:371-380

Possingham HP, Lindenmayer DB, Norton TW, Davies I (1994) Metapopulation viability analysis of the greater glider Petauroides volans in a wood production area. Biological Conservation 70:227-236

Pritchard JK, Stephens M, Donnelly P (2000) Inference of population structure using multilocus genotype data. Genetics 155:945-959.

Pritchard JK, Wen X, Falush D (2010) Documentation for Structure software: Version 2.3. http://pritch.bsd.uchicago.edu/structure.html.

Pyke GH (2002) A review of the biology of the southern bell frog Litoria raniformis (Anura: Hylidae). Australian Zoologist 32:32-48

Reed DH, Frankham R (2003) Correlation between fitness and genetic diversity. Conservation Biology 17:230-237

R Development Core Team (2012) R: A language and environment for statistical computing. R Foundation for Statistical Computing, Vienna, Austria. http://www.r-project.org/ 
Reh W, Seitz A (1990) The influence of land use on the genetic structure of populations of the common frog Rana temporaria. Biological Conservation 54:239-249

Robertson OJ, Radford JQ (2009) Gap-crossing decisions of forest birds in a fragmented landscape. Austral Ecology 34:435-446

Rousset F (2008) GENEPOP'007: a complete re-implementation of the GENEPOP software for Windows and Linux. Molecular Ecology Resources 8:103-106

Sagvik J, Uller T, Olsson M (2005) Outbreeding depression in the common frog, Rana temporaria. Conservation Genetics 6:205-211

Semlitsch RD (2002) Critical elements for biologically based recovery plans of aquaticbreeding amphibians. Conservation Biology 16:619-629

Semlitsch RD (2003) Conservation of pond-breeding amphibians In: Semlitsch RD (ed) Amphibian Conservation. Smithsonian Institution, Washington, pp 8-23

Sherman CDH, Wapstra E, Uller T, Olsson M (2008) Males with high genetic similarity to females sire more offspring in sperm competition in Peron's tree frog Litoria peronii. Proceedings of the Royal Society B: Biological Sciences 275:971-978

Sjögren-Gulve P (1994) Distribution and extinction patterns within a northern metapopulation of the pool frog, Rana lessonae. Ecology 75:1357-1367

Skerratt L, Berger L, Speare R, Cashins S, McDonald K, Phillott A, Hines H, Kenyon N (2007) Spread of chytridiomycosis has caused the rapid global decline and extinction of frogs. Ecohealth 4:125-134

Smith MA, Green DM (2005) Dispersal and the metapopulation paradigm in amphibian ecology and conservation: are all amphibians metapopulations? Ecography 28:110-128

Smouse PE, Long JC, Sokal RR (1986) Multiple regression and correlation extensions of the Mantel test of matrix correspondence. Systematic Zoology 35:627-632 
Smouse PE, Peakall R (2006) GENALEX 6: genetic analysis in Excel. Population genetic software for teaching and research. Molecular Ecology Notes 6:288-295

Stuart SN, Chanson JS, Cox NA, Young BE, Rodrigues ASL, Fischman DL, Waller RW (2004) Status and trends of amphibian declines and extinctions worldwide. Science 306:1783-1786

Suter W, Bollmann K, Holderegger R (2007) Landscape permeability: from individual dispersal to population persistence. In: Kienast F, Wildi O, Ghosh S (eds) A Changing World, vol 8. Landscape Series. Springer Netherlands, pp 157-174

Tallmon DA, Luikart G, Waples RS (2004) The alluring simplicity and complex reality of genetic rescue. Trends in Ecology and Evolution 19:489-496.

Trombulak SC, Frissell CA (2000) Review of ecological effects of roads on terrestrial and aquatic communities. Conservation Biology 14:18-30

UNFPA (2007) State of the World Population 2007: Unleashing the Potential Urban Growth. United Nations Population Fund, New York

Verboom J, Schotman A, Opdam PFM, Metz JAJ (1991) European nuthatch metapopulations in a fragmented agricultural landscape. Oikos 61:149-156

Vos CC, Antonisse-de Jong AG, Goedhart PW, Smulders MJM (2001) Genetic similarity as a measure for connectivity between fragmented populations of the moor frog (Rana arvalis). Heredity 86:598-608

Wassens S (2008) Review of the past distribution and decline of the Southern Bell Frog Litoria raniformis in New South Wales. Australian Zoologist 34:446-452

Wassens S, Watts RJ, Jansen A, Roshier D (2008) Movement patterns of southern bell frogs (Litoria raniformis) in response to flooding. Wildlife Research 35:50-58

Williams BK, Nichols JD, Conroy MJ (2002) The Analysis and Management of Animal Populations. Academic Press, San Diego 
603 Table 1. Sampling sites, number of individuals sampled $(N)$, observed heterozygosity $\left(H_{O}\right)$ 604 and expected heterozygosity $\left(H_{E}\right)$.

605

\begin{tabular}{cccccc}
\hline \multirow{2}{*}{ Site } & \multicolumn{2}{l}{ Coordinates } & & & \\
\cline { 2 - 3 } & Latitude & Longitude & $N$ & $H_{O}$ & $H_{E}$ \\
\hline S1 & -37.6857 & 144.9602 & 20 & 0.614 & 0.623 \\
S2 & -37.6852 & 144.9789 & 20 & 0.616 & 0.617 \\
\hline C1 & -37.6325 & 144.9579 & 20 & 0.714 & 0.681 \\
C2 & -37.6355 & 144.9639 & 19 & 0.679 & 0.688 \\
C3 & -37.6355 & 144.9684 & 20 & 0.723 & 0.677 \\
C4 & -37.6321 & 144.9669 & 3 & -- & -- \\
C5 & -37.6305 & 144.9607 & 4 & -- & -- \\
\hline N1 & -37.5453 & 144.9439 & 20 & 0.650 & 0.625 \\
N2 & -37.5411 & 144.9494 & 20 & 0.755 & 0.672 \\
N3 & -37.5407 & 144.9605 & 20 & 0.695 & 0.674 \\
N4 & -37.5422 & 144.9599 & 12 & 0.742 & 0.694 \\
N5 & -37.5388 & 144.9713 & 20 & 0.739 & 0.691 \\
\hline
\end{tabular}

606

607

608

609 
610 Table 2. Pairwise $F_{S T}$ values. The lower matrix displays the pairwise $F_{S T}$ values $\left(^{*}=\right.$ significant following sequential Bonferroni adjustment for

611 multiple statistical tests), and the upper matrix shows both the straight-line distance between sites (in meters) and the presence or absence of major

612 urban barriers between them (in parentheses, where $0=$ no barrier and $1=$ barrier present). Grey shading represents site clusters.

613

\begin{tabular}{l|cccccccccc}
\hline Site & S1 & S2 & C1 & C2 & C3 & N1 & N2 & N3 & N4 & N5 \\
\hline S1 & -- & $1616(1)$ & $6071(1)$ & $5557(1)$ & $5482(1)$ & $15664(1)$ & $16053(1)$ & $16073(1)$ & $15923(1)$ & $16264(1)$ \\
S2 & $0.059^{*}$ & -- & $6332(1)$ & $5712(1)$ & $5509(1)$ & $15896(1)$ & $16233(1)$ & $16154(1)$ & $16006(1)$ & $16252(1)$ \\
C1 & $0.082^{*}$ & $0.070^{*}$ & -- & $695(0)$ & $1111(0)$ & $9611(1)$ & $9986(1)$ & $10008(1)$ & $9857(1)$ & $10232(1)$ \\
C2 & $0.054^{*}$ & $0.065^{*}$ & 0.011 & -- & $463(0)$ & $10192(1)$ & $10547(1)$ & $10526(1)$ & $10367(1)$ & $10707(1)$ \\
C3 & $0.058^{*}$ & $0.060^{*}$ & 0.021 & 0.011 & -- & $10391(1)$ & $10724(1)$ & $10662(1)$ & $10513(1)$ & $10805(1)$ \\
N1 & $0.094^{*}$ & $0.134^{*}$ & $0.094^{*}$ & $0.073^{*}$ & $0.086^{*}$ & -- & $634(1)$ & $1542(1)$ & $1482(1)$ & $2477(1)$ \\
N2 & $0.087^{*}$ & $0.116^{*}$ & $0.060^{*}$ & $0.048^{*}$ & $0.047^{*}$ & $0.047^{*}$ & -- & $998(0)$ & $981(0)$ & $1935(0)$ \\
N3 & $0.078^{*}$ & $0.093^{*}$ & $0.048^{*}$ & $0.042^{*}$ & $0.042^{*}$ & $0.048^{*}$ & $0.028^{*}$ & -- & $152(0)$ & $941(0)$ \\
N4 & $0.077^{*}$ & $0.099^{*}$ & $0.044^{*}$ & $0.028^{*}$ & $0.028^{*}$ & $0.047^{*}$ & 0.015 & 0.003 & -- & $998(0)$ \\
N5 & $0.101^{*}$ & $0.113^{*}$ & $0.053^{*}$ & $0.053^{*}$ & $0.053^{*}$ & $0.068^{*}$ & $0.025^{*}$ & 0.018 & 0.017 & -- \\
\hline
\end{tabular}

614

615 
Figure 1. Map of the study area. Panel (a) shows the location of the study area in Victoria, on the northern outskirts of the Melbourne metropolitan area (grey shading). Panel $(b)$ displays the location of each site cluster (rectangles), with black dots in clusters representing sampling sites, and those in the surrounding landscape representing other locations known to be occupied by Litoria raniformis at the time of sampling. The grey shaded area depicts the distribution of major urban infrastructure (housing estates, industrial estates and dual-carriage roads). Panels $(c)-(e)$ display the distribution of the sampling sites in each of the northern, central and southern clusters, respectively. Grey shading again depicts the distribution of major urban infrastructure. The black lines in panels $(b)-(e)$ represent the Merri Creek and its tributaries.

628

Figure 2. Population structure of Litoria raniformis in the study area, as estimated by

Bayesian population clustering analysis. Each column represents a $Q$ value: the proportion which a given genotype belongs to a genetic unit of the given color. a) All sites from each of the three clusters; b) northern cluster; c) southern cluster. The central cluster did not display genetic subdivision, and is therefore not presented individually.

Figure 3. Plot of pairwise $F_{S T}$ against distance (in meters) for sites within the same cluster.

Site pairings separated by major urban barriers (dual-carriage roads, urban and industrial developments) are represented by filled circles; site pairings without urban barriers are represented by open circles. 


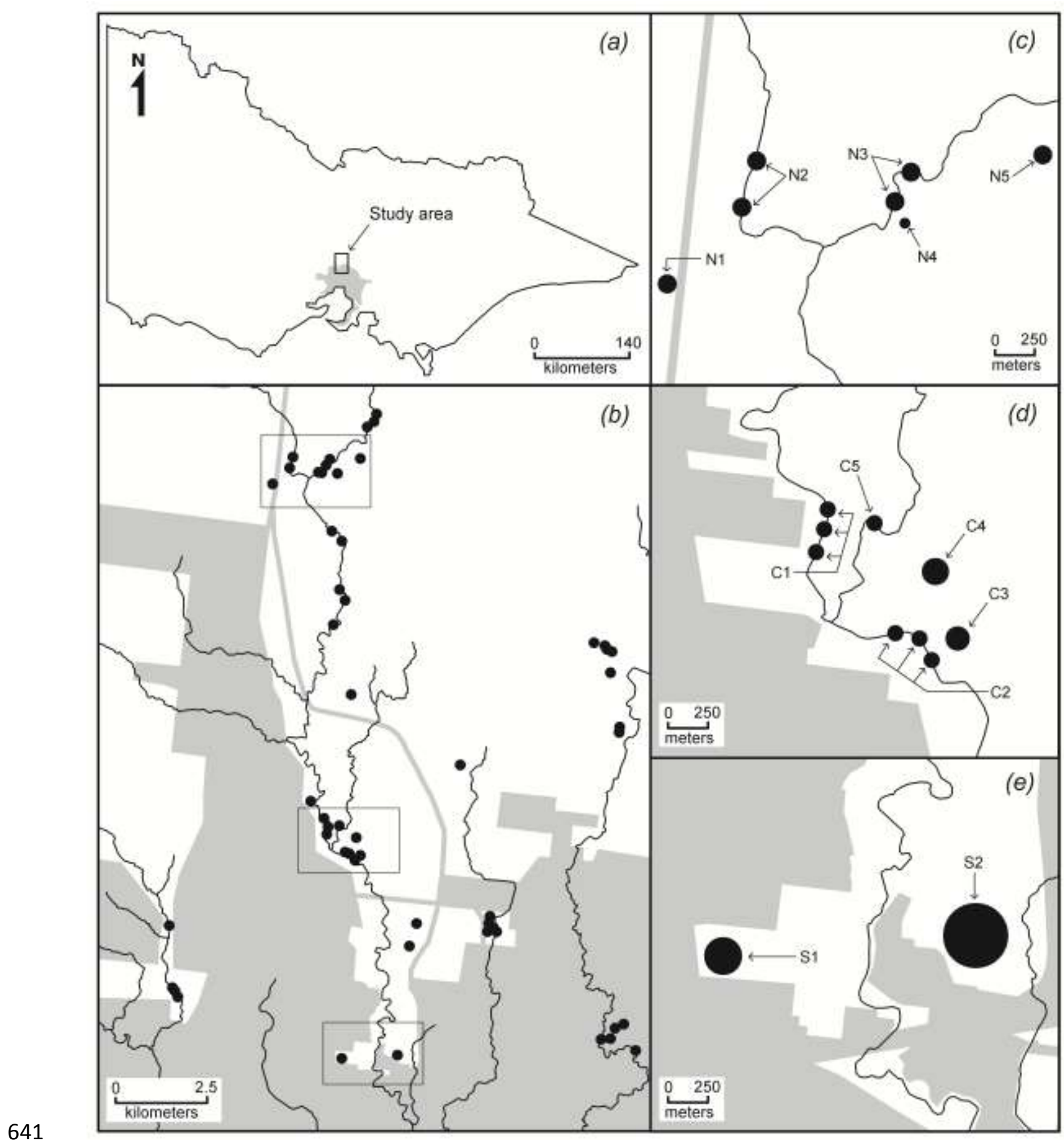

642

643

644

645

Figure 1

646 
651

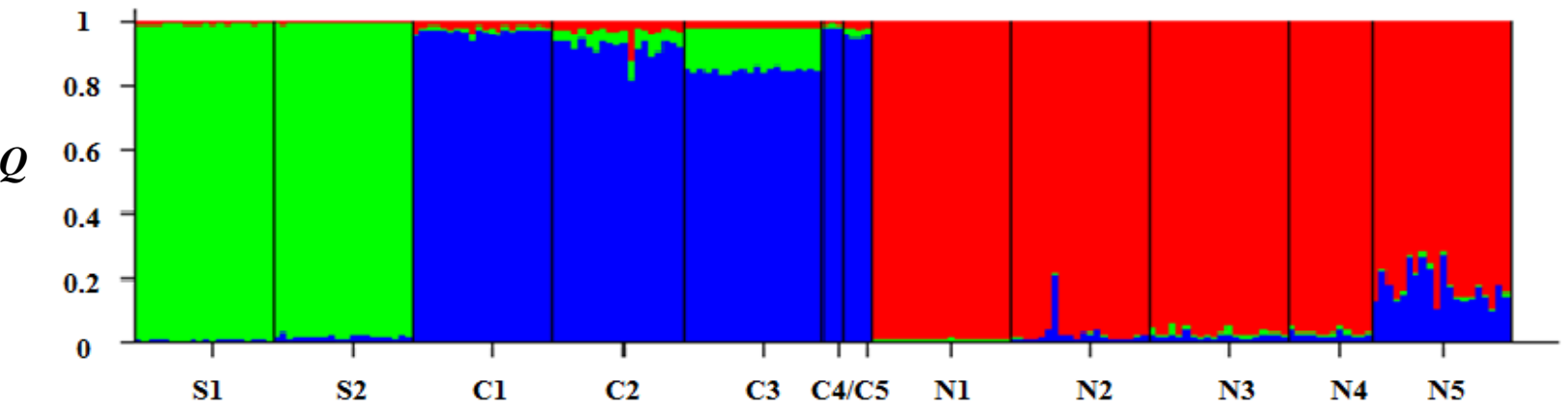

652

(b)

653

654

655

656

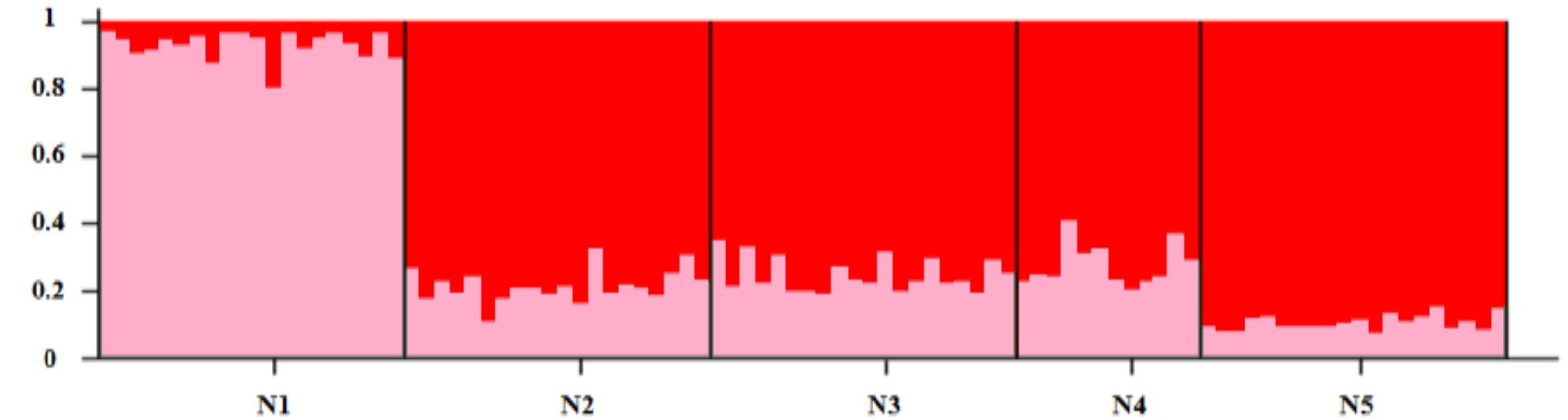

657

(c)

658

659

660

661

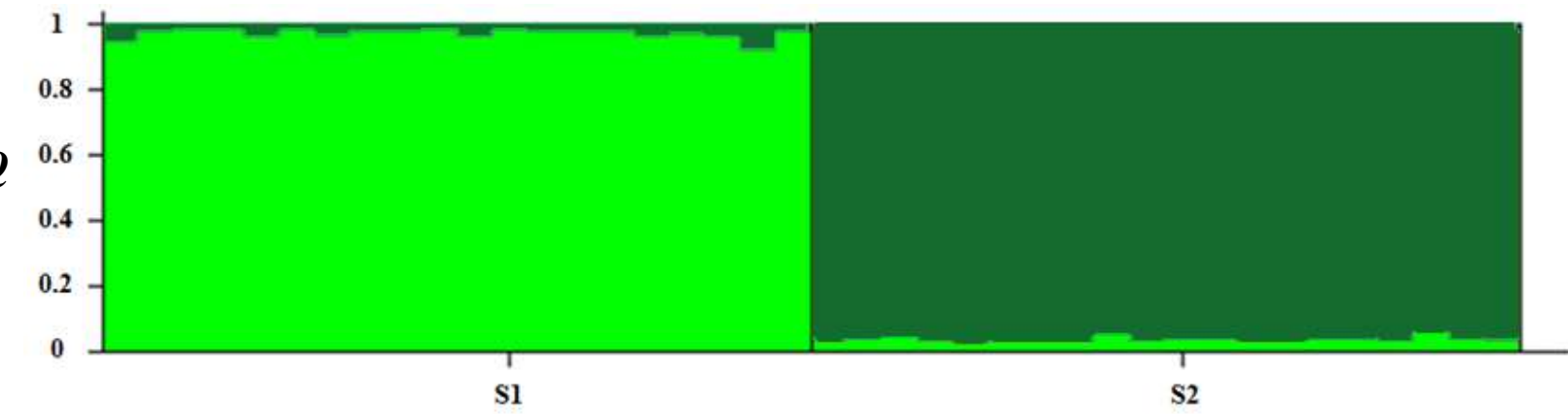

662

\section{Population}

663

664

665

666

Figure 2 


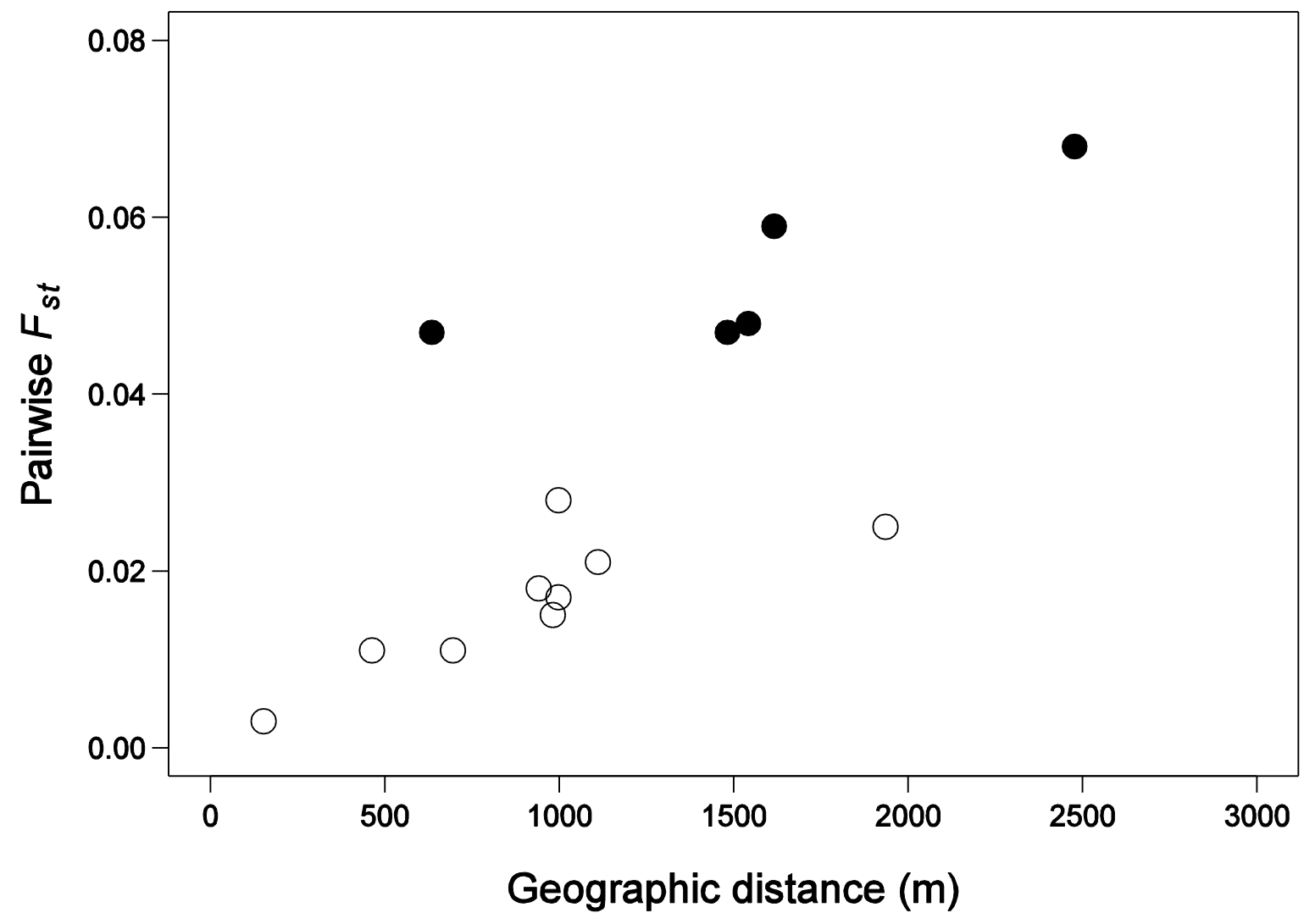

667

668

669

670

671

672

673

674

675

676

677

678

679

680

Figure 3 


\section{University Library}

\section{- M M N E R VA A gateway to Melbourne's research publications}

Minerva Access is the Institutional Repository of The University of Melbourne

Author/s:

Hale, JM;Heard, GW;Smith, KL;Parris, KM;Austin, JJ;Kearney, M;Melville, J

Title:

Structure and fragmentation of growling grass frog metapopulations

Date:

2013-04-01

Citation:

Hale, J. M., Heard, G. W., Smith, K. L., Parris, K. M., Austin, J. J., Kearney, M. \&

Melville, J. (2013). Structure and fragmentation of growling grass frog metapopulations.

CONSERVATION GENETICS, 14 (2), pp.313-322. https://doi.org/10.1007/

s10592-012-0428-9.

Persistent Link:

http://hdl.handle.net/11343/282679 